\title{
INFLUENCIA DE LA OBESIDAD EN LA ELIMINACION HEPATICA DE LA DEXMEDETOMIDINA
}

\author{
Augusto Rolle ${ }^{1}$, Mauricio Ibacache ${ }^{1}$, Sandra Solari ${ }^{1}$, Javiera Torres $^{1}$, Fidel Allende ${ }^{1}$, Luis Ignacio Cortínez \\ 1 División de Anestesiologia, Facultad de Medicina. Pontificia Universidad Católica de Chile.
}

Introducción: Los pacientes obesos alcanzan mayores concentraciones plasmáticas de dexmedetomidina que los no obesos al dosificarlos por peso real. Estas mayores concentraciones serán explicadas por una menor distribución a los tejidos grasos y por una alteración del metabolismo hepático en obesos mórbidos. Este último hallazgo no ha sido suficientemente estudiado.

Objetivo General: Describir el efecto de la obesidad en el clearance de eliminación de la dexmedetomidina, utilizando un análisis farmacocinetico.

Material y Métodos: Previa aprobación por comité de ética institucional y obtenido el consentimiento informado, se realizo estudio descriptivo, de corte transversal en pacientes programados para cirugía abdominal laparoscópica electiva, ASA I-III, 18-65 años, IMC 20-45 $\mathrm{kg} / \mathrm{m}^{-2}$. Previo a cirugía se mido masa grasa y magra por densitometria corporal total. La anestesia fue con propofol-remifentanil, ajustados por BIS y hemodinamia, más dexmedetomidina según peso magro, a $0,5 \mathrm{mg} / \mathrm{kg}$ por $10 \mathrm{~min} \mathrm{y}$ luego $0,5 \mathrm{mg} / \mathrm{kg} / \mathrm{h}$. Durante la cirugía, se realiza biopsia hepatica para evaluar score NAS (reflejo de enfermedad hepática no alcoholica), y muestras seriadas de sangre venosa durante $12 \mathrm{~h}$ para medición de dexmedetomidina plasmatica por HPLC. Se estimo flujo hepatico con método de indocianina verde (PDR), utilizando Monitor LiMON, $2 \mathrm{~h}$ post-cirugia. El análisis farmacocinetico fue con el programa NONMEM7.3. Se evaluo efecto de composición corporal, NAS y PDR en parametros farmacocineticos. Una disminución de la función objetiva de NONMEM (OFV, -2-Likelihood) $>3,83$ puntos equivale a $\mathrm{p}$ $<0,05$.

Resultados: Se estudiaron 40 pacientes. El área bajo la curva de dexmedetomidina (0-60 min) no presenta correlación con índice de masa corporal (Pearson $=0,27, \mathrm{p} 0,09)$, al dosificar a masa ma- gra. Un modelo de 2 compartimentos describio adecuadamente la farmacocinetica de dexmedetomidina. La masa magra medida fue el mejor descriptor de volúmenes y clearance de dexmedetomidina, al comparar con peso como descriptor $(\mathrm{OFV}=-8, \mathrm{p}<0,01)$. No se observo una influencia deleterea de la obesidad (masa grasa) en el clearance de eliminación de dexmedetomidina. No se encontro correlación entre covariables relacionadas a metabolismo hepático (gama glutamil transferasa, Pearson: $-0,022, \mathrm{p}=0,89$, y Score NAS, Spearman: $-0,017 \mathrm{p}=0,92)$, ni entre las relacionadas a flujo hepático (PDR, Pearson: $0,29, p=0,079$ ), con el clearance metabólico (figura 1); así como tampoco con el índice de masa corporal. Estas covariables no aportaron en la predicción del clearance metabólico de dexmedetomidina en esta población.

Conclusiones: Nuestro estudio confirma que la dosificación de dexmedetomidina debe ajustarse a masa magra en pacientes obesos. El hecho de no evidenciar ningún efecto negativo de la obesidad en el clearance del fármaco, sugiere que po-

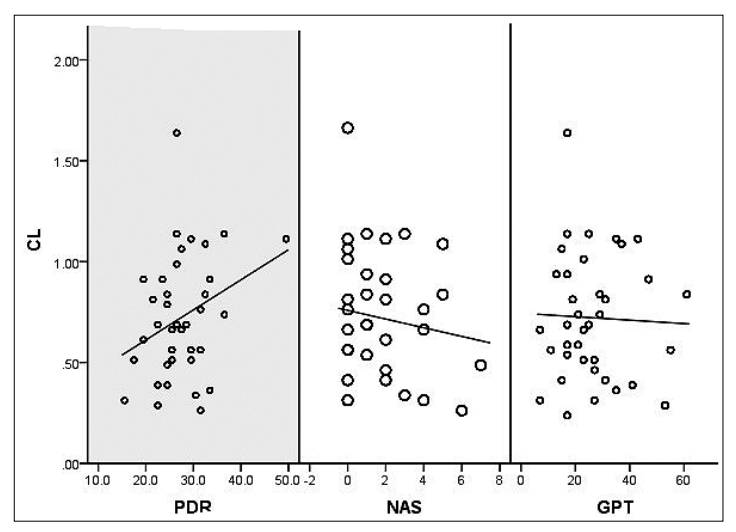

Figura 1. 
sibles efectos negativos anteriormente descritos en obesos, se deben a sobredosificación relativa y disminución secundaria del flujo hepático al dosificar por peso real.

Financiamiento: Proyecto FONDECYT 1150197.

\section{Referencias}

1. Cortínez L, et al. Dexmedetomidine pharmacokinetics in the obese. Eur J Clin Pharmacol (2015); 71:1501-08.

2. Green B, et al. What is the best size descriptor to use for pharmacokinetics studies in the obese? Br J Clin Pharmacol (2004); 58(2):119-33. 